\title{
DÜBLIN
}

Technological University Dublin

ARROW@TU Dublin

Articles

School of Chemical and Pharmaceutical

Sciences

2020

\section{An Ammonia Sensor Using an Unadorned Bromocresol Layer}

John Cassidy

Technological University Dublin, john.cassidy@tudublin.ie

Caoimhe Ní Néill

Technological University Dublin

Merve Akdağ

Fachbereich Chemieingenieurwesen Stegerwaldstraße Steinfurt Germany

See next page for additional authors

Follow this and additional works at: https://arrow.tudublin.ie/scschcpsart

Part of the Analytical Chemistry Commons

\section{Recommended Citation}

Cassidy, J.F. et al. (2020) An Ammonia Sensor Using an Unadorned Bromocresol Layer, International Journal of Environmental Analytical Chemistry. DOI: 10.1080/03067319.2020.1807975

This Article is brought to you for free and open access by the School of Chemical and Pharmaceutical Sciences at ARROW@TU Dublin. It has been accepted for inclusion in Articles by an authorized administrator of ARROW@TU

Dublin. For more information, please contact arrow.admin@tudublin.ie, aisling.coyne@tudublin.ie, gerard.connolly@tudublin.ie.

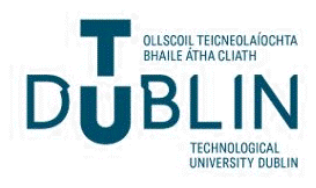




\section{Authors}

John Cassidy, Caoimhe Ní Néill, Merve Akdağ, and Tony Betts

This article is available at ARROW@TU Dublin: https://arrow.tudublin.ie/scschcpsart/101 
An Ammonia Sensor Using an Unadorned Bromocresol Layer

Caoimhe Ní Néill ${ }^{1,3}$, Merve Akdağ ${ }^{2}$, Anthony J. Betts ${ }^{3}$, John F. Cassidy *1,3

${ }^{1}$ School of Chemical and Pharmaceutical Sciences,

Technological University Dublin

City Campus, Kevin Street,

Dublin 8

Ireland

2. Merve Akdağ

Fachhochschule Münster (University of Applied Sciences Münster)

Fachbereich Chemieingenieurwesen

Stegerwaldstraße 39

48565 Steinfurt

Germany

${ }^{3}$ Applied Electrochemistry Group

Technological University Dublin

City Campus, Kevin Street,

Dublin 8

Ireland

*Corresponding author_John.cassidy@tudublin.ie 


\section{Abstract}

Bromocresol Purple,(BCP) cast onto an acetate sheet, was used to sense ammonia. This simple layer responded reversibly to a low concentration ( $15 \mathrm{ppm}$ ) of ammonia in the presence of water vapour. The BCP solution was spincoated on an acetate sheet from a solution in dichloromethane. This layer was exposed to nitrogen and $\mathrm{NH}_{3} / \mathrm{H}_{2} \mathrm{O}$ vapour in quick succession. The colour change occurred from yellow to purple rapidly in the solid state. The $\lambda_{\max }$ for the neutral ( acid) form of the BCP was found to be $435 \mathrm{~nm}$ and the $\lambda_{\max }$ for the dianion ( base form) of the BCP was found to be $610 \mathrm{~nm}$ A mechanism previously predicted theoretically was confirmed using FTIR identifying the presence of a peak associated with a carbonyl in the dianion form.

Keywords

Ammonia sensor, bromocresol purple, acetate sheet, colorimetric sensor

\section{Introduction.}

Ammonia is a toxic gas with a strong pungent odour and is harmful to humans and animals. It is used as an intermediate in the manufacture of cleaning agents, fertilisers, foodstuffs and pharmaceuticals along with being used as a refrigerant. The threshold limit of exposure in the workplace, specified by the Occupational Safety and Health Administration (OSHA), is 50 ppm[1]. Ammonia detection in the environment and particularly in the agriculture sector is important. A reliable in situ method of monitoring in real time would prove useful in a variety of fields. 
Various forms of ammonia sensors [2] have been developed such as high temperature metal oxide sensors [3,4], conducting polymer sensors [5-7] and sensors based on bromocresol purple (BCP ) immobilised in a sol gel [8,9]. However, these comprise layers which function at high temperatures or are quite complex to fabricate. A complex polydimethylsiloxanepolyurethane sponge decorated with $\operatorname{In}(\mathrm{OH})_{3}$ and bromocresol purple changed colour and wettability on exposure to ammonia[10]. A surface plasmon resonance based fibre optic sensor based on BCP coatings sputtered on either silver or gold on a silica fibre responded to ammonia up to $150 \mathrm{ppm} \mathrm{NH}_{3}$ [11]. BCP has been incorporated into a polyamide 6,6 nanofibres by electrospinning for use as an ammonia sensor [12,13]. More recently BCP has been incorporated into a microporous cellulose- based smart xerogel sensor [14]. Once again these are quite challenging to fabricate and in the latter case involves carboxymethylation of cellulose. In many of the aforementioned photometric systems the core transduction mechanism ( colour change) is the acid base conversion of BCP on exposure to what is a quite unique volatile base.

More recently, sensors have employed copper based composites or silver nanoparticles. $\mathrm{Cu}(\mathrm{II})$ doped cholesteric liquid crystals have been shown to experience a red shift of the $\lambda_{\max }$ on exposure to pure $\mathrm{NH}_{3}$ gas[15]. In addition a fluorescent and colorimetric sensor was based on $\mathrm{Cu}(\mathrm{II})$-2,7-bis(1-imidazole) fluorene DMF gel which responded to ammonia vapour with a limit of detection of $5 \mathrm{ppm}[16]$. Sensors using the surface plasmon resonance absorbance of silver nanoparticles were developed for ammonia in aqueous solutions[17,18]. In addition, a fluorescent sensing layer using chitosan nanoparticles derivatised with fluorescein isothiocyanate supported on cellulose responded to ammonia in the gas phase and in solution[19].

This present work aims to demonstrate that the BCP can act alone as an ammonia sensor. Here a simple spin coated bromocresol purple layer is employed as an optical ammonia 
sensor. As a thin solid film, it is remarkable that a rapid reversible colour change is observed on exposure to ammonia; this is facilitated by the presence of water vapour.

\section{Experimental.}

All Chemicals were purchased from Sigma Aldrich and used as received. $0.016 \mathrm{~g}$ of BCP was dissolved in water and made up to $100 \mathrm{~cm}^{3}$. After a 1 in 10 dilution the absorbance was measured at $430 \mathrm{~nm}$. A solution of BCP was made in dichloromethane and drop cast on an acetate sheet at $500 \mathrm{rpm}$. Spincoating was performed using a Spincoat G3P-8 spincoater on acetate sheets that can be cut to fit into a cuvette. UV Vis spectra and transients were collected using a Cary 50 UV Vis spectrometer.

Transients were collected using a 6 port valve system analogous to that used in HPLC as previously described[20,21]. The transition was from a flow of $\mathrm{N}_{2}$ toward the sensing layer to where the nitrogen is bubbled through a solution of $\mathrm{NH}_{4} \mathrm{OH}$. Typically a defined concentration of $\mathrm{NH}_{4} \mathrm{OH}$ was prepared in $0.1 \mathrm{M} \mathrm{NaOH}$. A flow rate of $500 \mathrm{~mL} / \mathrm{min}$ for nitrogen gas was used. FTIR was collected on an Avatar 370 FTIR ( Thermo Nicolet) with an ATR. Gastec tubes were used to monitor the $\mathrm{NH}_{3}$ concentration in the headspace of the cuvette

\section{Results and Discussion.}

From the UV Vis spectrum of bromocresol purple ( BCP) in slightly acidic aqueous solution, an absorbance of 0.55 was measured at $430 \mathrm{~nm}$, and with a molecular weight of $540 \mathrm{~g} \mathrm{~mole}^{-1}$, a molar extinction coefficient of $16800 \mathrm{dm}^{3} \mathrm{~mol}^{-1} \mathrm{~cm}^{-1}$ was calculated using the Beer Lambert law. This is similar to the literature value of $18,581 \mathrm{dm}^{3} \mathrm{~mol}^{-1} \mathrm{~cm}^{-1}$ [22]. Figure 1 shows a BCP layer spin coated on an acetate sheet. The $\lambda_{\max }$ for the neutral ( acid) form of the BCP was found to be $435 \mathrm{~nm}$ and the $\lambda_{\max }$ for the dianion (base form) of the BCP was 
found to be $610 \mathrm{~nm}$. This is slightly different to the $\lambda_{\max }$ in aqueous solution which are 430 $\mathrm{nm}$ and $588 \mathrm{~nm}$ for the acid and dianion forms respectively. This small difference is attributed to the difference between the solid state form of the dye and the solvated form in water. Differences in $\lambda_{\max }$ have previously been observed between the BCP in solution and BCP adsorbed on a polymethylmethacrylate matrix[23]. Using the solution based molar extinction coefficient at $430 \mathrm{~nm}$, the surface coverage of BCP on the acetate sheet was estimated to be $5.9 \times 10^{-8} \mathrm{~mol} \mathrm{~cm}{ }^{-2}$. When nitrogen was bubbled through a solution of $0.001 \mathrm{M} \mathrm{NH}_{4} \mathrm{OH}$ in $0.1 \mathrm{M} \mathrm{NaOH}$, the spectrum changed as can be seen in the dotted line in Figure 1 . Such spectral changes occur when BCP is in buffer solutions at different pHs since the pKa is reported to be 6.3 [24]

The spectrum in Figure 1 indicates that BCP behaves in a similar manner in its solid state to the behaviour in aqueous solution. In solution there are two peaks along with an isosbestic point indicating a transition between a neutral ( acid) state and a dianionic ( base) state. This simple configuration provides a non invasive environment for the dye. When BCP is immobilised in a sol gel fabricated from a mixture of tetraethoxysilane and methyltriethoxysilane, the dye behaviour is more complex with an intermediate zwitterionic species which has a $\lambda_{\max }$ of $470 \mathrm{~nm}$, stabilised by the ormosil content in the layer[9].

Separately when BCP is incorporated into crosslinked carboxymethyl cellulose, it also responds to ammonia in the presence of water vapour[14]. However in this case the $\lambda_{\max }$ for the immobilised dianion has shifted to $526 \mathrm{~nm}$ indicating that there is an interaction between the BCP and the supporting layer[14]. One layer, reported in the literature, where there is little influence of the supporting layer on the BCP, is a polydimethylsiloxanepolyurethane sponge decorated with $\operatorname{In}(\mathrm{OH})_{3}$. In this case the $\lambda_{\max }$ for the neutral ( acid) form is $440 \mathrm{~nm}$ and $595 \mathrm{~nm}$ for the dianion ( base) form. When BCP is sorbed onto PMMA, the 
$\lambda_{\max }$ for the acid form is $415 \mathrm{~nm}$, while for the dianion form it is $600 \mathrm{~nm}$ [23], which is similar to the $\lambda_{\max }$ values reported in this work.

Figure 2 shows that the transition from an acid state to a base state is quite rapid which is interesting in that it occurs in the solid state. This is by no means new as it has been observed while the dye is immobilised in a sol gel[9], or in a $600 \mu \mathrm{m}$ thick PMMA layer [23]. The transient in the sol gel configuration is slower because of the porous structure of the sol gel [9] . It can be seen from Figure 2 that the transformation from acid to base is more rapid than vice versa. Since the response if so rapid, it points to a very porous thin layer

Figure 3 shows that the signal does increase with ammonia concentration, though for this particular layer it saturated at high concentration. However the response is not linear with concentration. This nonlinearity has also been seen elsewhere for the ammonia responsive sponge [10], the cellulose based smart xerogel [14] and the sol gel system [9]. When a tube with $\mathrm{CaO}$ is introduced into the stream of gas, the signal is decreased which indicates that water does play a role in the response. The layer is equally fast at responding to low concentrations ( $15 \mathrm{ppm}$ from $0.001 \mathrm{M} \mathrm{NH}_{4} \mathrm{OH}$ ) of ammonia as it is to higher concentrations ( 45 ppm from $0.005 \mathrm{M} \mathrm{NH}_{4} \mathrm{OH}$ ). At much higher concentrations the response becomes diffusion controlled.

The role of a sensing device is to provide an immediate response to the appearance of a toxic gas, rather than relying on expensive instrumentation[15]. This layer of BCP, on its own, responds immediately to the presence of ammonia. It can be fabricated simply, by casting or spraypainting. As can be seen in Figure 2, it responds rapidly and reversible with a good signal to noise ratio to ammonia at a level of $15 \mathrm{ppm}$. The dynamic range is limited as can be seen in Figure 3. However, this can be tuned by varying the concentration of the BCP in dichloromethane. Typically, the device would be set to recognise ammonia concentrations 
above a certain threshold and the layer could be used as the sensing layer in a fibre optic spectrometer. One challenge of sensing layers is their selectivity to a particular analyte. In this case there are only a limited range of basic volatiles such as ethylene diamine which interfere with the response[16]

The BCP was cast onto an attenuated total reflection, ATR crystal from dichloromethane and the dichloromethane was allowed to evaporate. Figure 4 shows the FTIR spectrum of BCP before and after exposure to ammonia. There were peaks at similar to those in the literature (812 $\mathrm{cm}^{-1}, 1188 \mathrm{~cm}^{-1} 1345 \mathrm{~cm}^{-1}$ and $1482 \mathrm{~cm}^{-1}$ [25] . On exposure to $\mathrm{NH}_{3} / \mathrm{H}_{2} \mathrm{O}$ vapour, there is a colour change from yellow to purple. The appearance of a peak at $1590 \mathrm{~cm}^{-1}$ is indicative of the presence of a carbonyl in keeping with the mechanism predicted theoretically [24] shown in Figure 5. The transformation of conjugation in the mechanism is in keeping with the colour change unlike other proposed mechanisms[10]. $\mathrm{NH}_{4}{ }^{+}$acts as counterion to the dianionic form in the solid state.

\section{Conclusion}

Using a simple unadorned layer of BCP cast on an acetate sheet a sensing layer for $\mathrm{NH}_{3}$ was fabricated. This layer was found to respond quickly and reversibly to $\mathrm{NH}_{3}$. FTIR was used to confirm the transition from a neutral state to a dianion state.

\section{Conflict of Interest}

There is no conflict of interest

\section{Acknowledgement}


M.Akdağ thanks the European Commission for an Erasmus scholarship 
7. References

1. X. Liu, N. Chen, B.Q., Han, X.C Xiao, G. Chen, I. Djerdj and Y.D. Yang, Nanoscale, 7 (2015) 14872. $\quad \underline{\text { https://doi.org/10.1039/c5nr03585f }}$

2. B. Timmer, W. Olthuis and A. van der Berg, Sensors and Actuators B, 107 (2005) 666.

https://doi.org/10.1016/j.snb.2004.11.054

3. D.Z. Zhang, J.J .Liu, C.X. Jiang, A.M. Liu, and B.K Xia, Sensors and Actuators, B, 240 (2017) 55.

http://dx.doi.org/10/1016/j.snb.2016.08.085

4. T.T .Jiang, Z.J. Wang, Z.Y .Li, W. Wang, X.R Xu, X.C. Liu, J.F. Wang and C. Wang, J. Mater Chem. C 1 (2013) 3017.

https://doi.org/10.1039/c3tc00370a

5. M. Penza, E. Milella, F. Musio, M.B. Alba, G. Cassano, and A. Quirini, Materials Science and Engineering C, 5 (1998) 255.

6. X. Huang, N. Hu, R. Gao, Y.Yu, Y. Wang, Z. Yang, E. Kong, H.Wei and Y. Zhang,. Journal of Materials Chemistry, 22 (2012) 22488. 
https://Doi:10.1039/c2jm34340a

7. H.K.Chitte, N.V.Bhat, V.E.Walung, G.N.Shinde, J.Sensor Technology, 1 (2011) 47. https://doi:10.4236/jst.2011.12007

8. S. Tao, L. Xu and J.C. Fanguy, Sensors and Actuators B 115 (2006) 158. https://doi.org/10.1016/j.snb.2005.08.034

9. C. Malins, T.M. Butler and B.D. MacCraith, Thin Solid Films, 368 (2000) 105.

10. J. Guo, Z. Bai, Y. Lyu, J. Wang and Q Wang, Analyst, 143 (2018) 3390.

https://doi.org/10.1039/c8an00388b

11. P. Bhatia and B.D. Gupta, Plasmonics, 8, (2103)779. https://doi.org/10.1-07/s11468$\underline{012-9472-\mathrm{Z}}$

12. L. van der Schueren, T. Mollet, O.Ceylan and K.de Clerck, European Polymer Journal, 46 (2010) 2229. https://doi.org/10.1016/j.eurpolymj.2010.09.016

13. Y. Zhang, J.J. Kim, D. Chen, H.L. Tuler and G.C. Rutledge, Advanced Functional Materials, 24 (2014) 4005.

14. T.A. Khattab, S. Dacrory, H. Abou-Yousef and S. Kamel, Carbohydrate Polymers , 210 (2019) 196. https://doi.org/10.1016/j.carpol.2019.01.067 
15. S.Dai, N.Prempeh, D.Liu, Y.Fan, M.Gu and Y.Chang, Carbohydrate Polymers, 174, ( 2017), 531.

http://dx.doi.org/10.1016/j.carbpol.2017.06.098

16. Y. Cheng, Q.Feng, M.Yin, C.Wang and Y.Zhou, Tetrahedron Letters, 57 ( 2016), 3814.

http://dx.doi.org/10.1016/j.tetlet.2016.07.013

17. A. Amirjani and D.Haghshenas Fatmehsari, Talanta 176 ( 2018), 242.

http://dx.doi.org/10.1016/j.talanta.2017.08.022

18. A. Buccolieri, A.Serra, G.Giancane, and D.Manno, Beilstein Journal of Nanotechnology, 9, (2018), 499.

http://doi:10.3762/bjnano.9.48

19. T.A.Khattab, N.F.Kassem, A.M.Adel and S.Kamel, J. Fluorescence, 29 (2019), 693.

https://doi.org/10.1007/s10895-019-02381-5

20. A.C. Power, J.F. Cassidy and A.J .Betts, , ECS Transactions, 19 (2009) 181. : https://doi.org/10.1149/1.3118551

21. A.C.Power, A.J. Betts and J.F. Cassidy, The Analyst 135 (2010) 1645.

https://doi.org/10.1039/c0an00133c

22. D.Whitney King, D.R. Kester, Applied Spectroscopy, 44 (1990) 722.

23. N.A. Gavrilenko, N.V. Saranchina, A.V. Sukhanov, D.A. Fedan, Mendeleev Commun. 28 (2018) 450. 
Https://doi.org/10.1016/j.mencom.2018.07.038

24. T.de Meyer, K. Hemelsoet, V. van Speybroeck and K.de Clerck, Dyes and Pigments, 102 (2014) 241.

http://dx.doi.org/10.1016/j.dyepig.2013.10.048

25. SBDS Spectrum of Bromocresol Purple, KBr disk accessed April 2019. 


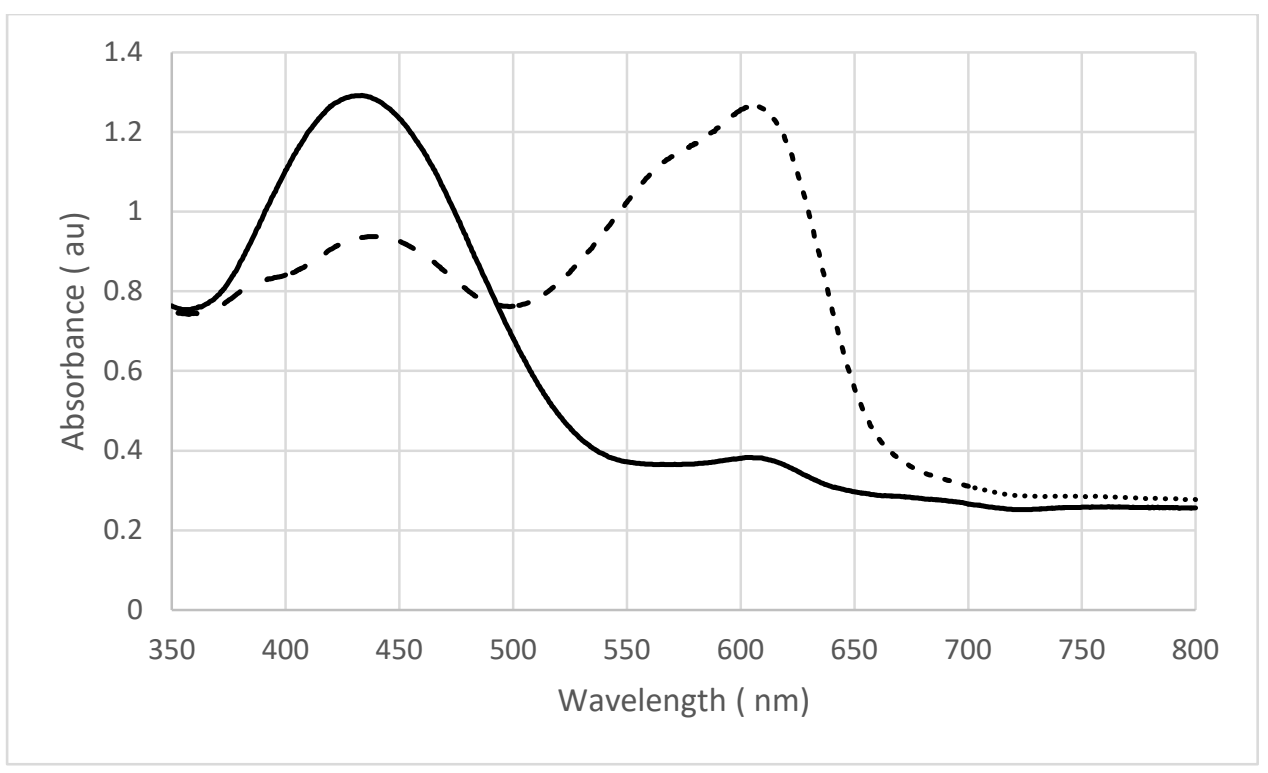

Figure 1 Spectrum of BCP cast on an acetate sheet before ( full line ) and after exposure to $\mathrm{NH}_{3} / \mathrm{H}_{2} \mathrm{O}$ vapour ( dotted line)

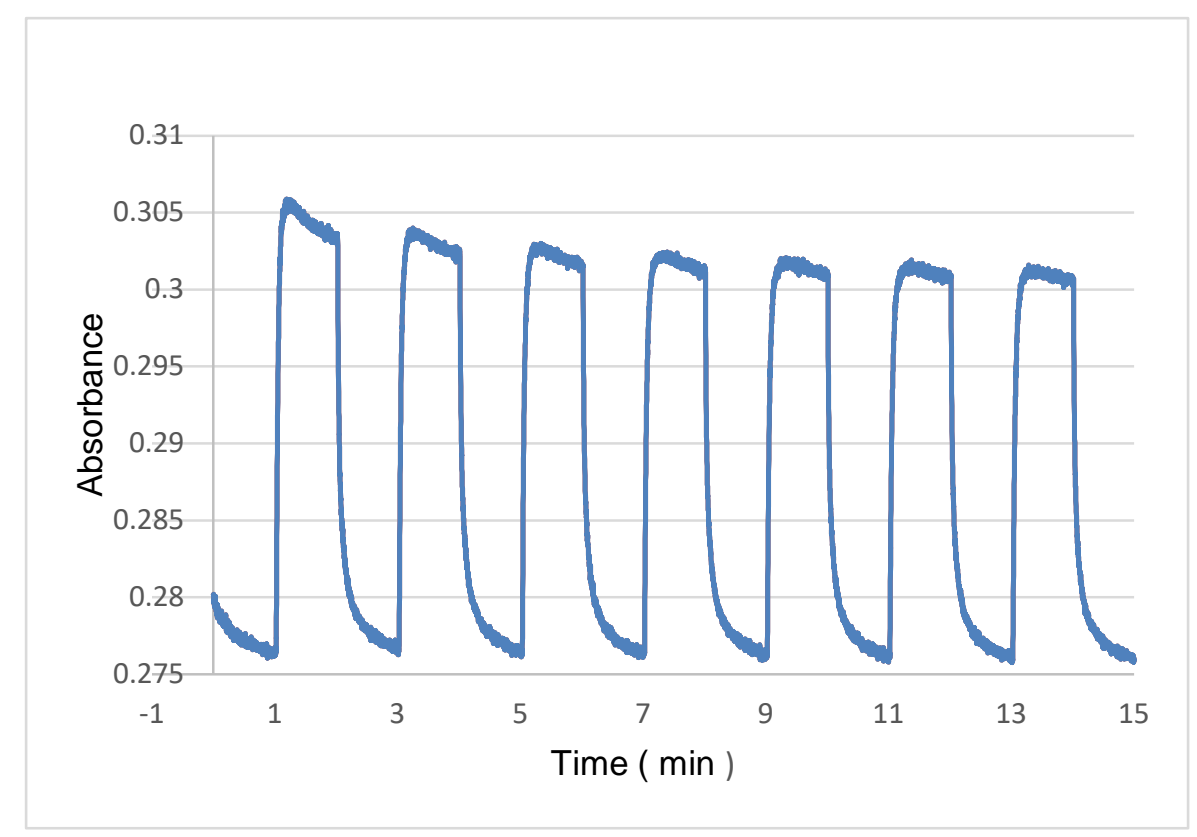

Figure 2 Transient collected at $\lambda=588 \mathrm{~nm}$ from bubbling nitrogen through a solution of $0.001 \mathrm{M} \mathrm{NH}_{4} \mathrm{OH}$ and 0.01M NaOH. Vapour concentration determined by a Gastec tube indicated an ammonia concentration of 15 ppm. 
Page 14 of 19 


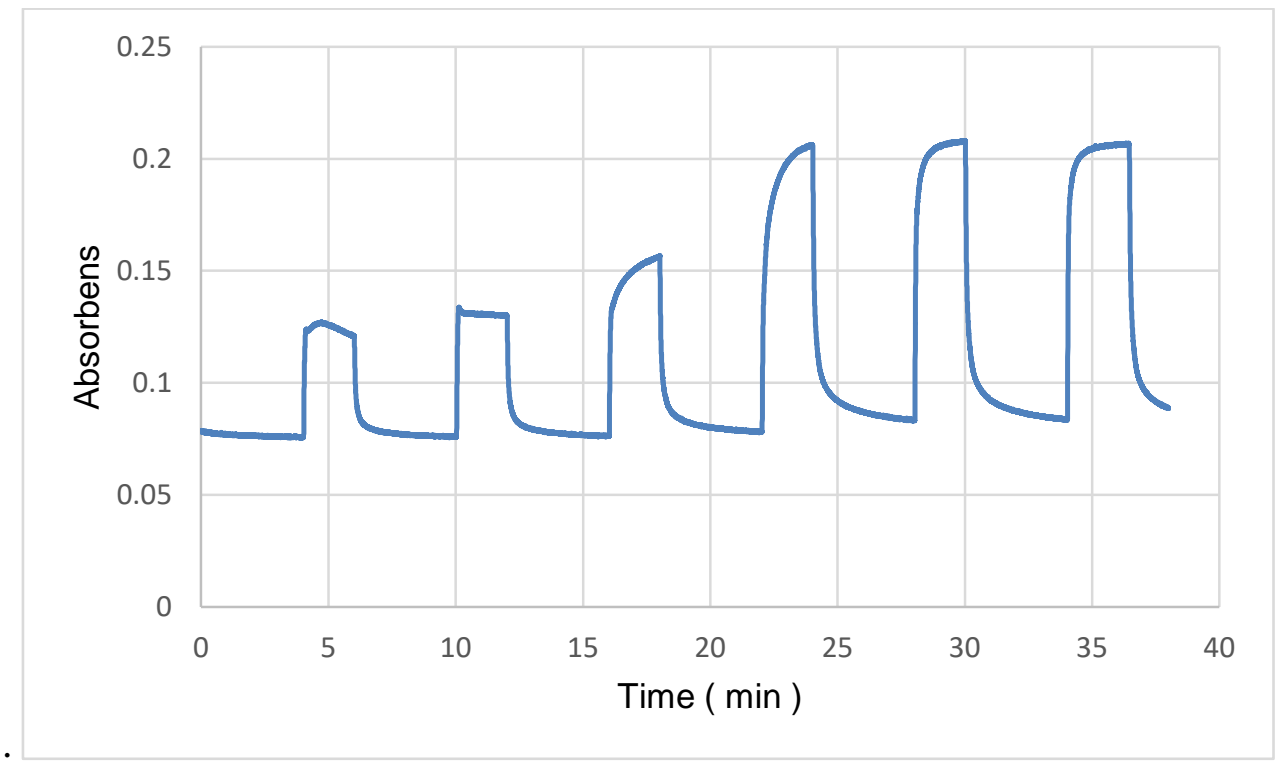

Figure 3 Transients of nitrogen bubbling through solutions of increasing $\mathrm{NH}_{4} \mathrm{OH}$ concentrations : $0.001 \mathrm{M}, 0.005 \mathrm{M} 0.01 \mathrm{M}, 0.05 \mathrm{M}, 0.1 \mathrm{M}$ and $0.5 \mathrm{M}$, all in $0.1 \mathrm{M} \mathrm{NaOH}$, interspersed with exposure to $\mathrm{N}_{2}$. It can be seen that the signal increases with concentration, but that the signal is saturated at high concentrations. The $\mathrm{NH}_{3}$ concentration for the $0.005 \mathrm{M}$ solution was found to be 45 ppm using a Gastec tube. 

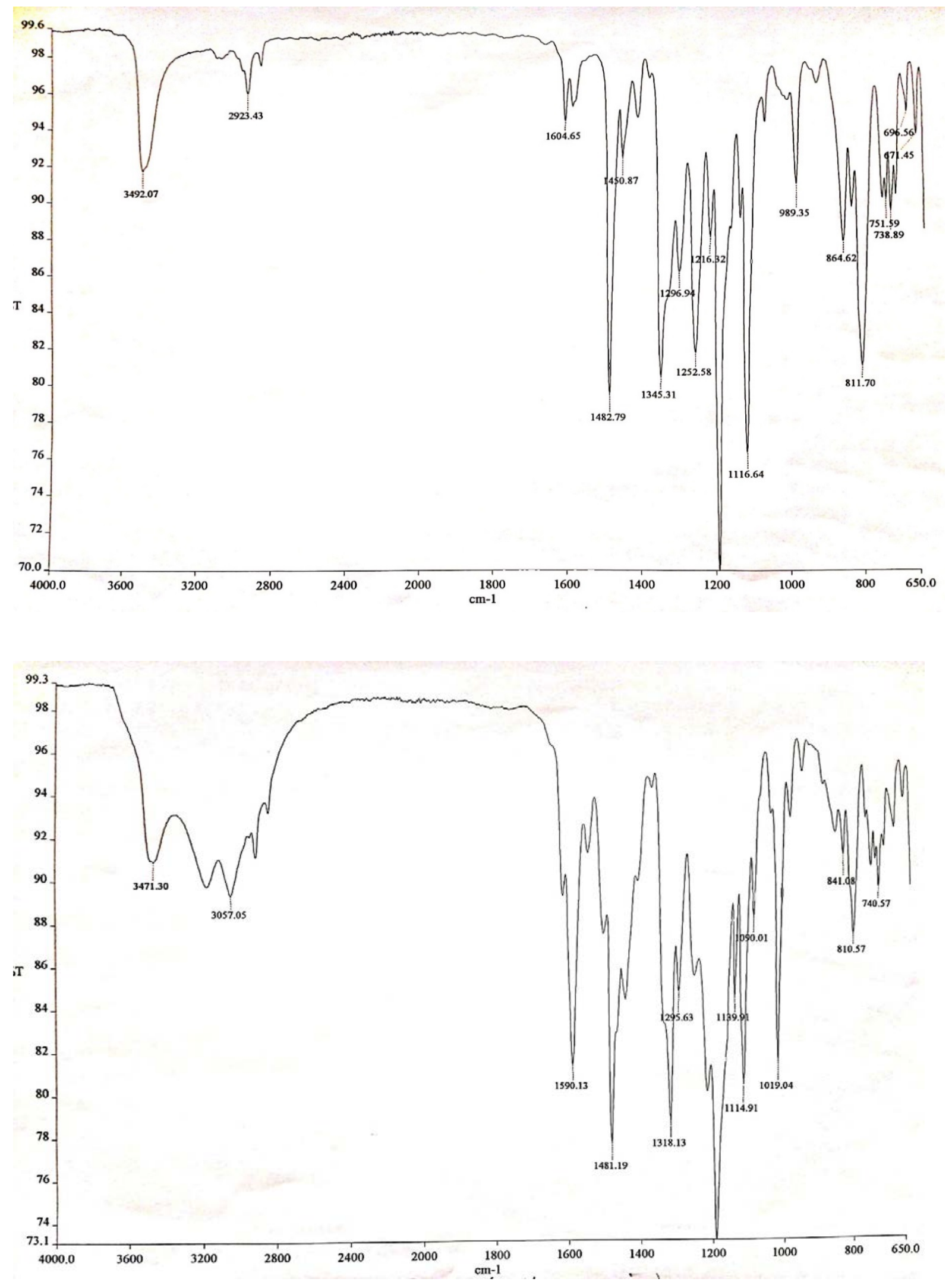

Figure 4 FTIR spectrum of BCP layer coated on ATR before (top) and after ( bottom ) exposure to $\mathrm{NH}_{3}$ 
Page $\mathbf{1 7}$ of $\mathbf{1 9}$ 

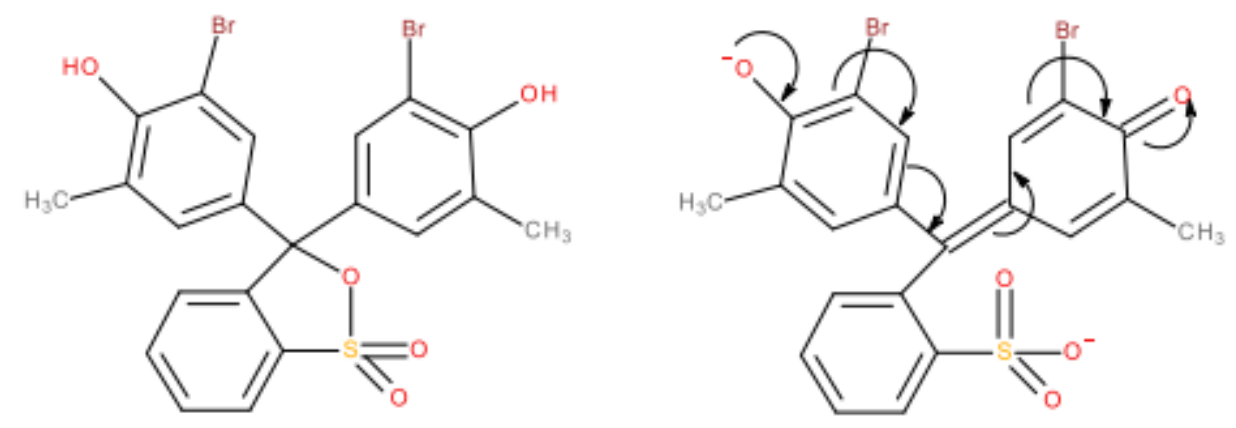

Figure 5, the proposed structural change from the neutral acid form ( LHS) to the Base form (RHS), facilitated by a two step process involving solvation with $\mathrm{H}_{2} \mathrm{O}$ followed by deprotonation by $\mathrm{NH}_{3}$.[24] . Charge neutrality is maintained by forming the ammonium salts, facilitated by the presence of water. 
Page 19 of 19 